\title{
PRODUCTION AND CHARACTERIZATION OF ANTIMICROBIAL ACTIVE COMPOUNDS FROM THE CYANOBACTERIUM NOSTOC COMMUNE VAUCH
}

\author{
Abdel Hameed M.S. ${ }^{\text {a,b }}$, Hassan S.H. ${ }^{\text {a,c*}, ~ A b d e l ~ S a l a m ~ R . ~}{ }^{\text {d }}$, Gamal R. ${ }^{a}$ \\ a. Botany Department, Faculty of Science, Beni-Suef University, Egypt \\ b. Biology Department, Faculty of Science, Jazan University, KSA \\ c. Medical laboratory Science Department, College of Applied Medical \\ Science, Al Jouf University, KSA \\ d. Pharmacognosy Department, Faculty of Pharmacy, Beni Suef University, \\ Egypt
}

\begin{abstract}
In this investigation, antimicrobial activity of Nostoc commune Vauch (isolated from agricultural wastewater canal, Beni Suef Governorate, Egypt) organic extracts were examined against nine selected microbial isolates. Four of them were Gram positive bacterial isolates (Bacillus subtilis, Mycobacterium phlei, Sarcina maxima and Staphylococcus aureus), four Gram negative bacteria (Escherichia coli, Proteus mirabilis, Pseudomonas aeruginosa and Salmonella arizonae) and one unicellular fungus (Candida albicans) were evaluated for their resistance against these extracts. Methanol was the best organic solvent for extraction of active material, rather than the other organic solvents. This material was produced, maximally, after 10 days of incubation in aerated shaken culture at $30^{\circ} \mathrm{C}$ and $\mathrm{pH} 8.0$ when $N$. commune was grown in Medium 18 growth medium. The antagonistic material was purified using thin layer chromatography then identified using chromatographic and spectroscopic techniques including UV, FT-IR, mass spectrophotometer and proton-NMR. Four unknown compounds were extracted that had long chain alcohol, sterol, long chain fatty acid and triterpen. These compounds were tested for their antimicrobial activity against $B$. subtilis. Only the long chain fatty acid (compound C) had an inhibitory effect on the growth of $B$. subtilis while the other compounds were not active.
\end{abstract}

Key words: Nostoc commune, antimicrobial activity, organic extract

\section{Introduction}

Cyanobacteria (blue-green algae) are a group of extraordinary diverse Gramnegative prokaryotes that originated 3.5 billion years ago (Kaushik et al., 2008). The medicinal and nutrient qualities of cyanobacteria were first appreciated as early as $1500 \mathrm{BC}$, when Nostoc species were used to treat gout, fistula and several forms of cancer (Liu and Chen, 2003). Various strains of cyanobacteria are 
known to produce intracellular and extracellular metabolites with diverse biological activities such as antibacterial (Falch et al., 1995; Mundt et al., 2003; Kaushik and Chauhan, 2008) and antifungal (MacMillan and Tadeusz, 2002). Some of these metabolites have potential or development of new pharmaceutical compounds. Mundt et al. (2003) proved that the cyanoboacterium Oscillatoria redekei produce fatty acids which show antibacterial activity. The methanol extracts from Chlorococcum strain HS-101 and Dunaliella primolecta strongly inhibited the growth of a strain of methicillin resistant Staphylococcus aureus, which cause serious problems in Japanese hospitals (Ohta et al., 1995). Ostensvik $\boldsymbol{e t}$ al. (1998) examined five strains of cyanobacteria for antibacterial activity and found that the methanol extracts from Tychonema bourrellyi, Aphanizomenon flos-aquae and Cylindrospermopsis raciborskii showed the most pronounced inhibitory effects against the Bacillus cereus and B. subtilis. The aim of this investigation was to isolate $N$. commune and test its antimicrobial activity against some bacterial and fungal species. Furthermore, some experiments were done for purification of the active components and elucidation of their chemical structure.

\section{Material and Methods}

\section{Organism and growth conditions}

$N$. commune Vauch was isolated from agricultural wastewater canal, Beni Suef Governorate, Egypt. The dilution culture technique adopted by Venkataraman (1969) was used for isolation and purification. The isolated species was identified according to El-Nayal (1935) and Prescott (1951 and 1969). The isolated organisms were grown autotrophically in Medium 18 medium (Inthorn et al., 1996) at $28 \pm 2^{\circ} \mathrm{C}$ and continuous light intensity of $2600 \mathrm{LUX}$ for 20 days. The culture was grown in triplicate axenically by using the method recommended by Bolch and Blackburn (1996).

\section{Extract preparation}

Eight days old $N$. commune culture was centrifuged and the pellets were dried in hot air oven $\left(60^{\circ} \mathrm{C}\right)$ till constant weight and used for extraction of antimicrobial agents. Twenty gram of Nostoc dry weight was extracted separately by either chloroform, acetone, ethanol or methanol using Soxhlet extractor. After $6 \mathrm{~h}$ of extraction the solvents were evaporated from crude extract by rotary evaporator and collected in pre-weighed test tubes and then preserved at $4^{\circ} \mathrm{C}$ till use (Solomon et al. 2005).

\section{Antimicrobial activity test}

The test organisms used for antimicrobial evaluation were nine, four of them were Gram positive bacterial isolates (Bacillus subtilis, Mycobacterium phlei, 
Sarcina maxima and Staphylococcus aureus), four Gram negative bacteria (Escherichia coli, Proteus mirabilis, Pseudomonas aeruginosa and Salmonella arizonae) and one unicellular fungus (Candida albicans). These test organisms were deposited as culture collection at Botany and Microbiology Dept., Faculty of Science, Al-Azhar University, Cairo, Egypt. Screening for antibiotic activity of the tested cyanobacterial extracts was carried out by the agar diffusion assay according to European Pharmacopoe (1997). One loop full of each test organism was suspended in $3 \mathrm{ml} 0.85 \%$ sterile $\mathrm{NaCl}$ solution, separately. Nutrient agar (Difeco, UK) was inoculated with this suspension of the respective organism and poured into a sterile Petri dish. According to preliminary test for the most effective dose, $10 \mu \mathrm{l}$ of dimethyl sulfo-oxide (DMSO) contained $2 \mathrm{mg}$ of each extract was placed on sterilized paper disc $(6 \mathrm{~mm}$ diameter). The loaded discs were placed apart from each other on the inoculated agar plate aseptically. Sterilized discs that loaded with DMSO only served as negative control and antibiotic discs (Ampecillin $10 \mu \mathrm{g}$, Ciprocin, $30 \mu \mathrm{g}$ and Cephalothin, $30 \mu \mathrm{g}$ ) served as positive control. A pre-diffusion for $3 \mathrm{~h}$ was carried out at $10^{\circ} \mathrm{C}$ (Bansemir et al., 2006). Inhibition zones were measured after $24 \mathrm{~h}$ incubation period at $37^{\circ} \mathrm{C}$ for bacteria and at $30^{\circ} \mathrm{C}$ after $48 \mathrm{~h}$ for the fungus species. The inhibition zones were measured in $\mathrm{mm}$, triplicates were maintained and the mean values were obtainable.

\section{Column chromatograph}

The dried methanol extract of $N$. commune (one gm) from 20 gm dry weight was dissolved in a small amount of methanol with $5 \mathrm{~g}$ silica gel then dried under vacuum and inserted on the top of silica gel column $(150 \mathrm{~g}, 120 \times 5 \mathrm{~cm})$ packed by wet method with n- hexane. The column was eluted initially with n-hexane followed by gradient elution from $100 \% \mathrm{n}$ - hexane to $100 \%$ methanol. The effluent was collected in fractions $(50 \mathrm{ml}$ each). Each fraction was concentrated under reduced pressure and then subjected to TLC examination. The spots were located by means of para anisaldehyde acid followed by heating at $110{ }^{\circ} \mathrm{C}$ for 5 minutes. The purified fraction was lyophilized and subjected to the following analyses in order to recognize its structure as much as possible.

1- Shimadzu- 265 spectrophotometer for determination of ultraviolet absorption spectra.

2- Shimadzu- IR- 435 infrared spectrophotometer.

3- Joel NMR spectrometer, $500 \mathrm{MHZ}$.

4- Joel mass spectrometer, $70 \mathrm{eV}$. 


\section{Results}

\section{Antimicrobial activities of Nostoc commune}

The antimicrobial activity was evaluated as the diameters of the inhibition zones formed as a result of disc assay method in case of bacteria and fungi. Table 1 showed that the methanol extract of $N$. commune had more activity for most of test organisms than ethanol extract that recorded $13 \mathrm{~mm}$ of inhibition zone in case of Bacillus subtilis. On the other hand, this extract didn'h show any activity against Salmonella arizonae and Proteous mirobili. Meanwhile, chloroform and acetone extracts were not active against the all investigated microbes (data not shown).

Table (1): The antimicrobial activities of Nostoc commune extracts

\begin{tabular}{|c|c|c|c|c|c|}
\hline \multirow[b]{2}{*}{ Test microbes } & \multicolumn{2}{|c|}{ Organic extracts } & \multicolumn{3}{|c|}{ Reference antibiotics } \\
\hline & Ethanol & Methanol & $\begin{array}{c}\text { Ampicillin } \\
10 \mu \mathrm{g}\end{array}$ & $\begin{array}{c}\text { Ciprocin } \\
30 \mu \mathrm{g}\end{array}$ & 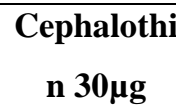 \\
\hline Bacillus subtilis & 10 & 13 & - & 20 & - \\
\hline Mycobacterium phlei & 11 & 12 & - & 20 & - \\
\hline Sarcina maxima & 7 & - & - & 20 & - \\
\hline $\begin{array}{l}\text { Staphylococcus } \\
\text { aureus }\end{array}$ & 10 & 12 & - & 24 & - \\
\hline Escherichia coli & 9 & 12 & - & 20 & - \\
\hline Proteus mirabilis & - & - & - & 20 & - \\
\hline $\begin{array}{l}\text { Pseudomonas } \\
\text { aeruginosa }\end{array}$ & 9 & 11 & - & 23 & - \\
\hline Salmonella arizonae & - & - & - & 16 & - \\
\hline Candida albicans & 7 & 12 & - & 18 & - \\
\hline
\end{tabular}

Influence of different culture conditions on the production of the antimicrobial material

\section{Effect of aeration}

Figure 1 illustrated the effect of methanol extract of $N$. commune when it was grown at aeration growth condition on $B$. subtilis to produce an inhibition zone of $12 \mathrm{~mm}$ after 8 days of incubation period. While in static condition (without air bubbling) the inhibition zone reached its maximum $(10 \mathrm{~mm})$ after 10 days of Nostoc incubation period (Fig. 1)

Egyptian J. of Phycol. Vol. 13, 2012 - 110 - 


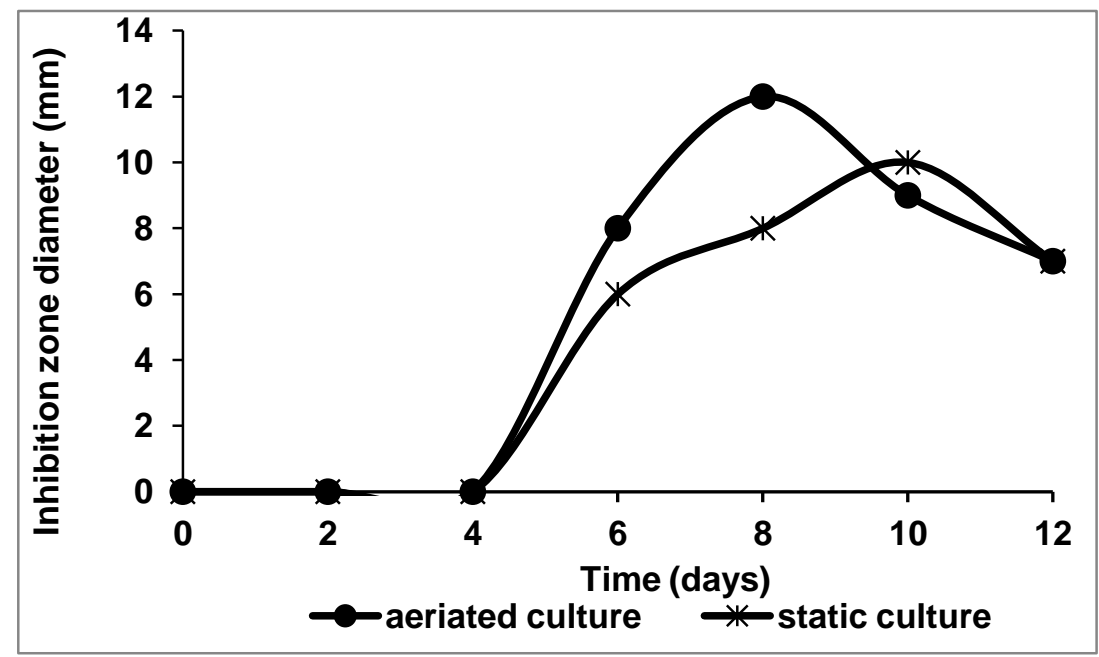

Fig. 1. Effect of static and aerated condition on the antimicrobial activity production of Nostoc commune.

\section{Effect of different culture media}

$N$. commune exhibited its antimicrobial activity against B. subtilis when incubated in various growth media but in different pattern ranged between 6 to 13 $\mathrm{mm}$ inhibition zones (Fig. 2). The highest zone diameter was obtained in M18 medium.

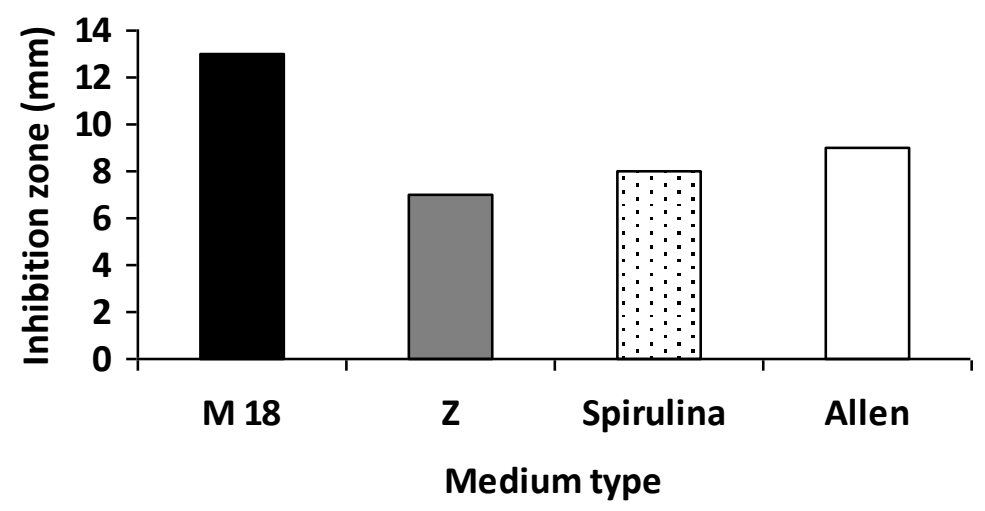

Fig. 2. Antimicrobial activities by Nostoc commune grown in different growth media. 
Effect of the pure extracted compounds from $N$. commune against $B$. subtilis

Four pure fractions were extracted from the crude methanol extract of $N$. commune. These fractions were labeled A, B, C and D. Fractions A, B and D didn't have any inhibition effect on B. subtilis. Whereas fraction $\mathrm{C}$ recorded 16 $\mathrm{mm}$ inhibition zone at concentration of $1 \mathrm{mg}$ loaded disc. The reference antibiotic Ciprocin $(30 \mu \mathrm{g})$ showed more activity against B. subtilis and gave $20 \mathrm{~mm}$ inhibition zone, on the other hand Cephalothin $(30 \mu \mathrm{g})$ and Ampicillin $(10 \mu \mathrm{g})$ didn't show any activity.

\section{Elucidation of the chemical structure of the isolated pure compound $(\mathrm{C})$ from} N. commune

The suggested structures of the purified extracted compound have been confirmed by UV, FT-IR, proton magnetic resonance and mass spectroscopy.

\section{Physical and chromatographic studies}

The active extracted compound (C) characterized by white powder, was soluble in hexane and chloroform and was sparingly soluble in methanol. The compound appeared as a single spot on the TLC plate and when sprayed by para anisaldehyde sulphuric acid reagent gave gray color with $R_{f}=0.1$. This spot was scratched and dissolved in solvent system of $n$-hexan: chloroform $(9: 1, \mathrm{v} / \mathrm{v})$. This extract was centrifuged to remove any unwanted material from the TLC silica gel. The supernatant was dried and stored at $4{ }^{\circ} \mathrm{C}$ till use.

\section{Spectroscopic studies}

\section{a- UV spectral analysis}

It showed UV absorption with $\lambda$ max below $230 \mathrm{~nm}(\approx 209 \mathrm{~nm})$ (Fig. 3)

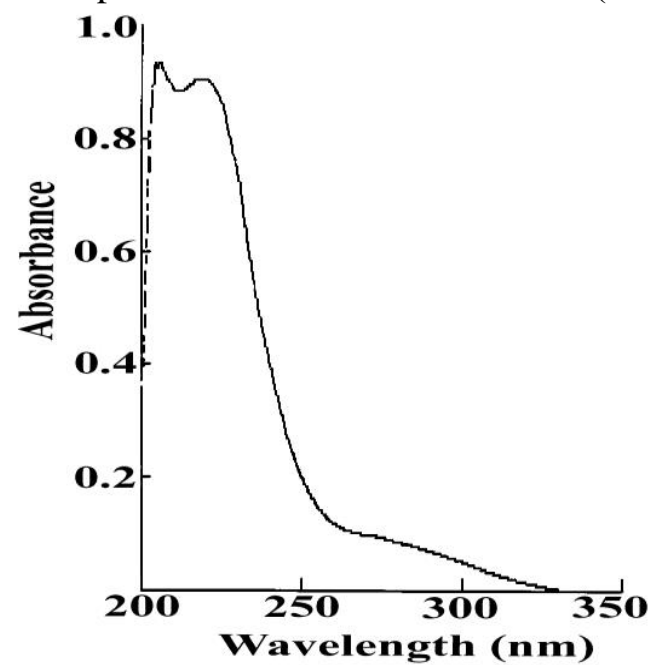

Fig. 3. UV spectrum of the bioactive compound (C) of $N$. commune 


\section{b- FT-IR spectral analysis}

The IR $\left(\mathrm{cm}^{-1}\right)$ spectrum of compound (C) revealed presence of the following absorption bands at $v \max \left(\mathrm{cm}^{-1}\right): 3430,2924,1630$ and 1453, 1178 that were characteristic of $\mathrm{COOH}$ stretching, $\mathrm{CH}$ stretching, $\mathrm{C}=\mathrm{O}$ and $\mathrm{CH}$ bending, respectively (Fig. 4).

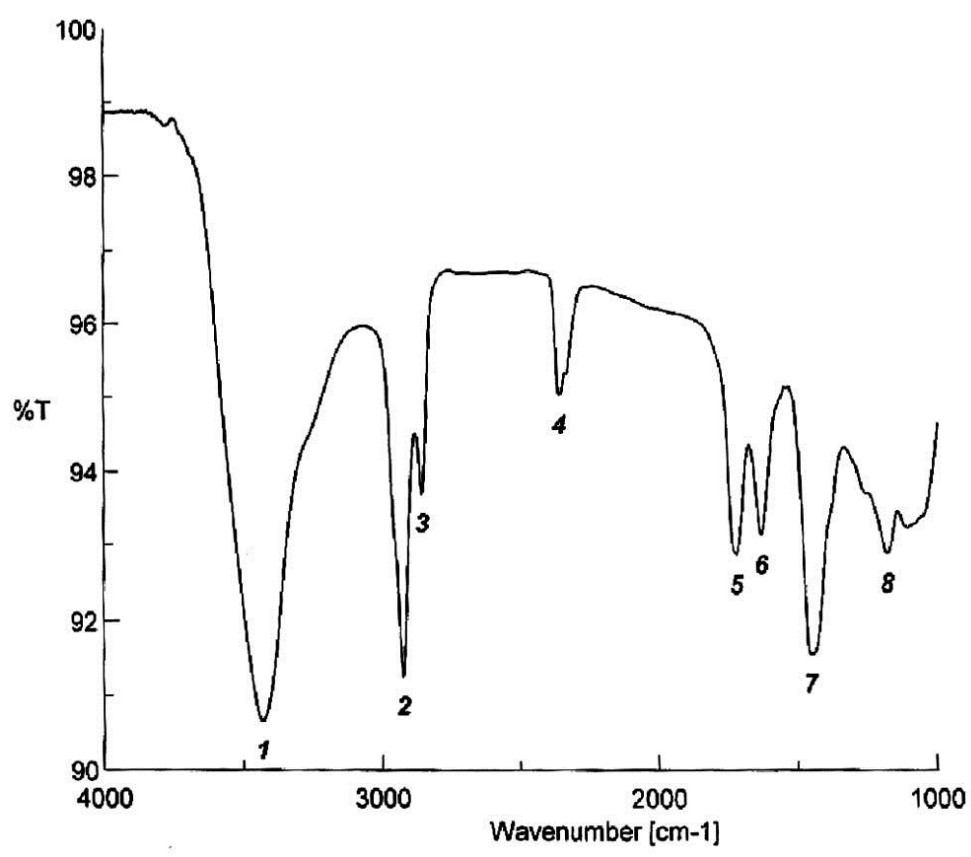

Fig. 4. FT-IR spectrum of the bioactive compound (C) of N. commune

\section{c- ${ }^{1}$ HNMR studies $\left(\right.$ CDCL $\left._{3}, 500 \mathrm{MHz}\right)$}

${ }^{1}$ HNMR showed several peaks in the aliphatic region [1-2ppm] and one peak for $\mathrm{CH}$ proton at 2.35 for $\mathrm{CH}$ group adjacent to $\mathrm{COOH}$ group (Fig. 5) So compound (C) was suggested to be a long chain of a fatty acid. 


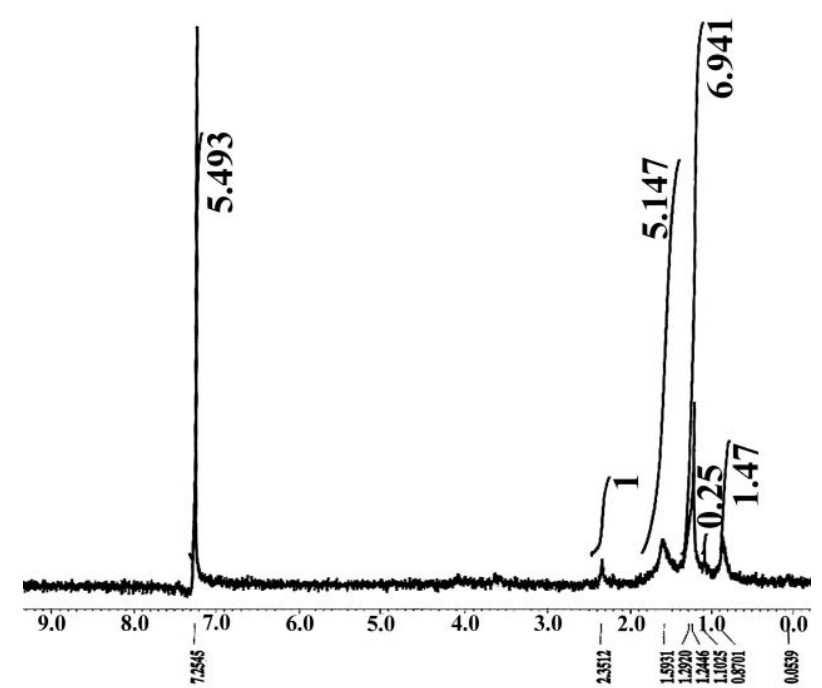

Fig. 5. ${ }^{1} \mathrm{HNMR}$ spectrum of the bioactive compound (C) of $N$. commune

\section{d- Mass spectroscopic analysis}

The mass spectrum of compound (C) showed a molecular ion peak at 636 $\mathrm{m} / \mathrm{z}(30 \%)$, base peak at $621 \mathrm{~m} / \mathrm{z}$, in addition to several peaks at 565, 551, 423 and $382 \mathrm{~m} / \mathrm{z}$. So we could suggest a molecular formula of the extracted compound (C) was $\mathrm{C}_{43} \mathrm{H}_{86} \mathrm{O}_{2}$ and its suggested chemical structure was illustrated by Figure (6).

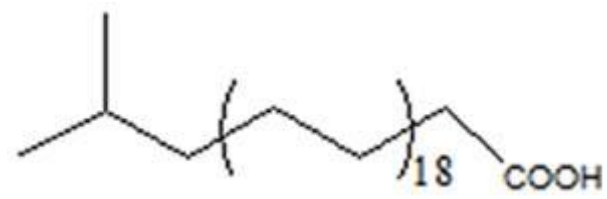

Fig. 6 The suggested chemical structure of the purified compound (C) isolated from Nostoc commune

\section{Discussion}

This study was done to evaluate the strength of Nostoc commune to generate antimicrobial active compounds against some microbes. The production of biologically active compounds by any organism culture requires studying the culture conditions that enhancing this activity. Almost all of the biologically active compounds of interest are secondary metabolites and thus are usually most abundant in stationary phase or in slow-growing cultures (Borowitzka, 1995). The present investigation indicated that, $N$. commune produced the antimicrobial 
material optimally at the stationary phase when it was cultured under shacked conditions and reached the maximal values after eight days of incubation. The antibiotic cyanobacterin LU1 from $N$. linckia was synthesized throughout the growth cycle (Gromov et al., 1991). Oufdou et al. (2001) found that, the extracellular and intracellular products released by the cyanobacterium Pseudanabaena sp. in the stationary growth phase, reduced the survival of E. coli, Salmonella sp., S. aureus and C. albicans. Our results were in agreement with Bloor and England (1991) who found that, the highest antimicrobial activity of $N$. muscorum achieved by day 14 of the cultivation.

We aimed to optimize suitable conditions to maximize the secondary metabolites production by $N$. commune. This organism was subjected to further studies to obtain the most favorable culture conditions under which it produced high values of the antagonistic material. This activity was indicated by the formation of inhibition zones against Gram-positive bacterium (B. subtilis).

The highest antimicrobial activity was recorded under aerated shacking condition and this finding was in agreement with Piccardi et al. (2000), who found that high antibacterial and antifungal activities were produced from Nostoc sp. when incubated in an orbital shaker flushed with a mixture of air:CO2 (95:5, v:v). M18 medium proved to be the best for the production of antimicrobial substance and formation of inhibition zones.

Methanol was the best solvent for extraction of the active material that produced by $N$. commune. Ostensvik et al. (1998) have found that methanol extracts made from Tychonema bourrellyi, Anabaena flos-aquae and Cylindospermopsis raciborskii showed the most pronounced inhibitory effects where an aqueous extracts made from Microcystis aeruginosa and T. bourrellyi possessed evident antibacterial properties. Mynderse and Moore (1977) extracted debromoaplysiatoxin (alkalylphenol) from the cyanobacteria Lyngbya sp. and $N$. muscorum with a mixture of chloroform and methanol $(1: 2, \mathrm{v} / \mathrm{v})$. The antimicrobial activity produced by the experimental organism ( $N$. commune) was subjected to series of experiments aiming to identify its chemical composition. The antimicrobial material was purified by using preparative TLC and silica gel column chromatography. The chromatographic studies of one gram total methanol extract of $N$. commune resulted in the isolation and purification of four compounds (A, B, C and D). In the present work we used UV spectra, NMR, IR and mass spectra data to elucidate the chemical composition of the antimicrobial active compound produced by Nostoc commune. The IR spectrum indicated the presence of $\mathrm{OH}$ and ester functionalities and ${ }^{1} \mathrm{H}-\mathrm{NMR}$ spectrums indicated the presence of 13-glycosidic linkage. Gromov et al. (1991) showed that cyanobacterin LU-l produced by $N$. linckia had a characteristic UV spectrum with maximum absorbance at $210 \mathrm{~nm}, 266 \mathrm{~nm}$ and $300 \mathrm{~nm}$. Juttner et al. (2001) elucidated the chemical structure of Nostocyclamide M, a cyanobacterial cyclic 
peptide with allelopathic activity from Nostoc 31, by chemical degredation detailed NMR and mass spectroscopic analyses. The purified extracted compounds were long chain alcohol, sterol, triterpen and long chain fatty acids. These compounds were tested for their biological activities against $B$. subtilis and showed that compound $(\mathrm{C})$ produced the highest growth inhibition with $B$. subtilis while compounds A, B and D were not active. The spectroscopic studies suggested that compound (C) was a long chain of fatty acid. The saturated fatty acids caprylic, capric, lauric, myrestic and the un-saturated ones, palmitaleic, oleic, linoleic and linolenic acids separated in Oscillatoria extracts were demonstrated to have antimicrobial activities against Gram - ve, Gram + ve bacteria and pathogenic fungi as reported by different studies (Fei et al., 2002; Ghazala et al., 2004; Krasnoff et al., 2005). Sabine et al. (2003) founded that fatty acids inhibited the growth of B. subtilis SBUG 14, Micrococcus flavus SBUG 16, Staphylococcus aureus SBUG 11 and ATCC 25923, but no activity was observed against multi resistant $S$. aureus strains.

In conclusion, more chemical analyses must be carried out to elucidate the complete structure of the obtained and purified compound from our isolate as the amount obtained from these fractions in Nostoc commune was very little.

\section{References}

Bloor, S. and England, R.R. (1991). Elucidation and optimization of the medium constituents controlling antibiotic production by the cyanobacterium Nostoc muscorum. Enzyme and Microbial Technology, 13: 76-81.

Bolch, C.J.S. and Blackburn, S.I. (1996). Isolation and purification of Australian isolates of the toxic cyanobacterium Microcystis aeruginosa. Kutz. Journal of Applied Phycology, 8: 5-13.

Borowitzka, M.A. (1995). Microalgae as sources of pharmaceuticals and other biologically active compounds. Journal of Applied Phycology, 7: 3-15.

El-Nayal, A. A. (1935). Egyptian fresh water algae, Faculty of Science Bulletin $106 \mathrm{pp}$.

European Pharmacopoeia (1997). Mikrobiologische Wertbestimmung von Antibiotika, Diffusions method. (6 ${ }^{\text {th }}$ Ed.) Deutscher-Apotheker-Verlag, Stuttgart, section 2.7.2.

Falch, B.S.; König, G.M.; Wright, A.D.; Sticher, O.; Angerhofer, C.K.; Pezzuto, J.M. and Bachmann, H. (1995). Biological activities of cyanobacteria: evaluation of extracts and pure compounds. Planta Medica, 61: 321-328.

Fei, T.D.; Jing, W.R.; Ming, L. and Xin, L.Y. (2002). Studies on chemical compositions and antimicrobial activity of volatile oil of Dictyophora echinovolvata. Mycosystema 21: 228-233. 
Ghazala, B.; Shameel, M.; Choudhary, M.I.; Shahzad, S. and Leghari, S.M. (2004). Phycochemistry and bioactivity of Zygnema (zygnemophyceae) from Sindh. International Journal of Biology and Biotechnology, 1: 335-342.

Gromov, B.V.; Vepritskiy, A.A.; Titova, N.N.; Mamkayeva, K.A. and Alexandrova, O.V. (1991). Production of the antibiotic cyanobacterin LU-I by Nostoc linckia CALU 892 (cyanobacterium). Journal of Applied Phycology, 3: 55-59.

Inthorn, D.; Nagase, H.; Isaji, Y.; Hirata, K. and Miyamoto,K. (1996). Removal of cadmium from aqueous solution by the filamentous cyanobacterium Tolypothrix Tenuis. Journal of Fermentation and Bioengineering, 82: 580-584.

Juttner, F.; Todorova, A.K.; Walch, N. and Philipsborn, W. (2001). Nostocyclamide M: A cyanobacterial cyclic peptide with allelopathic activity from Nostoc 31. Phytochemistry, 57 (4): 613 -619.

Kaushik, P. and Chauhan, A. (2008). In vitro antibacterial activity of laboratory grown culture of Spirulina platensis. Indain Journal of Microbiology, 48: 348-352.

Kaushik, P.; Chauhan, A.; Chauhan, G. and Goyal, P. (2008). Evaluation of Nostoc commune for potential antibacterial activity and UV-HPLC analysis of methanol extract. The Internet Journal of Microbiology, 5:1.

Krasnoff, S.B.; Reategui, R.F.; Wagenaar, M.M.; Gloer, J.B. and Gibson, D.M. (2005). Cicadapeptins I and II: new Aib-containing peptides from the entomopathogenic fungus Cordyceps heteropoda. Journal of Natural Products, 68: 50-55.

Liu, X.J. and Chen, F. 2003. Cell differentiation and colony alteration of Nostocflagelliforme, an edible terrestrial cyanobacterium, in different liquid suspension culture. Folia microbiologica, 48:619-626.

MacMillan, J.B. and Tadeusz, F.M. (2002). Caylobolide A, a unique 36membered macrolactone from a Bahamian Lyngbya majuscula. Organic Letters, 4: 1535-1538.

Matern, U.; Oberer, L.; Erhard, M.; Herdman, M. and Weckesser, J. (2003). Hofrnannolin a cyanopeptolin from Scytonema hofmanni PCC 7110. Phytochemistry, 64: 1061-1067.

Mundt, S.; Kreitlow, S. and Jansen, R. (2003). Fatty acids with antibacterial activity from the cyanobacterium Oscillatoria redekei HUB051. Journal of Applied Phycology, 15: 263-267.

Mynderse, J.S. and Moore, R.E. (1977). Antileukemia activity in the Oscillatoriaceae: isolation of debromoaplysiatoxin from Lyngbya. Science, 196: 538-539. 
Ohta, S.; Shiomi, Y.; Kawashima, A.; Aozasa, 0.; Nakao, T.; Nagata, T.; Kitamura, K. and Miyata, H. (1995). Antibiotic effect of linolenic acid from Chlorococcum strain HS -101 and Dunaliella primolecta on methicillin-resistant Staphylococcus aureus. Journal of Applied Phycology, 7: 121-127.

Ostensvik, O.; Skulberg, O.M.; Underdal, B. and Hormazabal, V. (1998). Antibacterial properties of extracts from selected planktonic fresh water cyanobacteria-a comparative study of bacterial bioassays. Journal of Applied Microbiology, 84: 1117-1124.

Oufdou, K.; Mezrioui, N.; Oudra, B.; Loudiki, M.; Barakate, M. and Sbiyya, B. (2001). Bioactive compounds from Pseudanabaena species (Cyanobacteria). Microbios, 106: 21-29.

Piccardi, R.; Frosini, A.; Tredici, R.M. and Margheri, C.M. (2000). Bioactivity in free -living and symbiotic cyanobacteria of the genus Nostoc. Journal of Applied Phycology, 12: 543 -547.

Prescott, G. W. (1951). Algae of the Western Green Lakes area exclusive of desmids and diatoms. Cranbrook Institute of Science, Bloomfield Hills, Michigan, 946 pp.

Prescott, G. W. (1969). The algae. A review. Michigan State University, Butler and Tanner Ltd., Frome and London, Great Br. 355 pp.

Sabine, M.; Susann, K. and Rolf, J. (2003). Fatty acids with antibacterial activity from cyanobacterium Oscillatoria redekei HUB 051. Journal of Applied Phycology, 15: 263-267.

Solomon, R.D.J.; Kallidass, S. and Vimalan, J. (2005). Isolation, identification and study of antimicrobial property of a bioactive compound in an Indian medicinal plant Acalypha indica (Indian-nettle). World Journal of Microbiology and Biotechnology, 21: 1231-1236.

Venkataraman, G.S. (1969). The cultivation of algae. Published by Indian Council of Agricultural Research, New Delhi. 


\section{انتاج و توصيف للمركبات النشطة كمضادات للميكروبات من الطحلب السيانوبكتيري Nostoc commune Vauch}

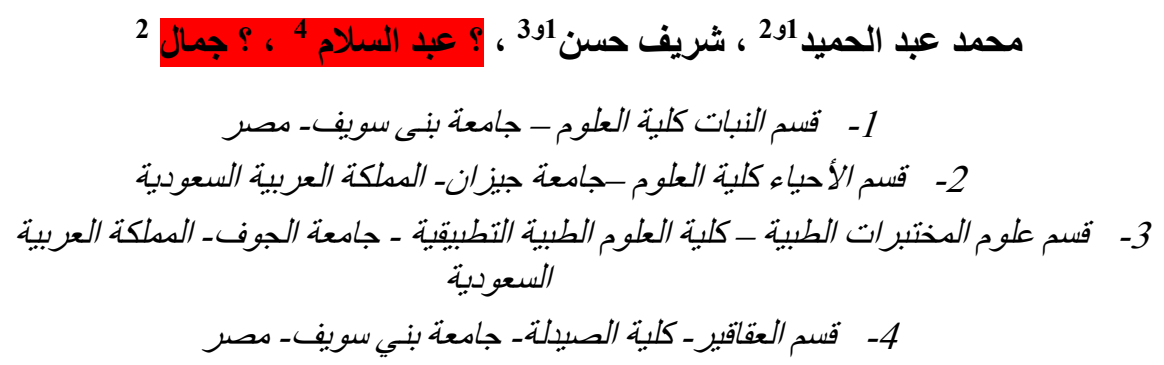

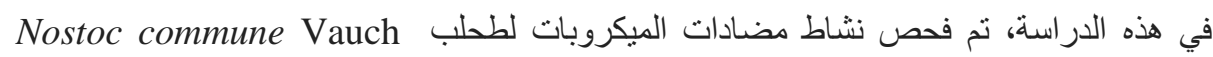

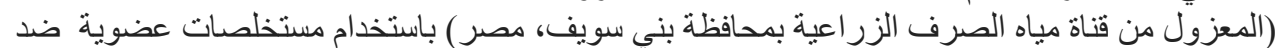

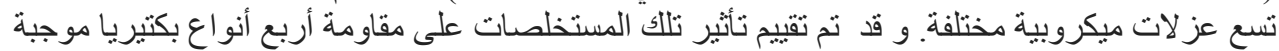

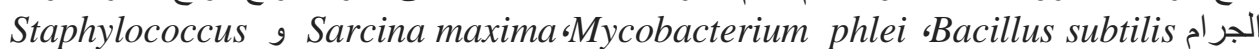
، Proteus mirabilis،Escherichia coli) و و و أربع أنواع أخرى من بكتيريا سالبة الجرام (aureus (Salmonella arizonae و و نوع و واحد من الفطريات وحيدة الخلية (Candida albicans)

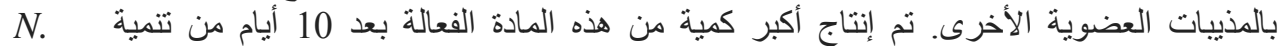
commune

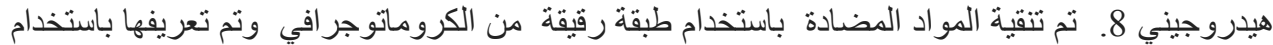

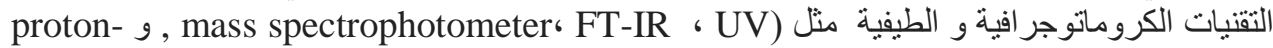

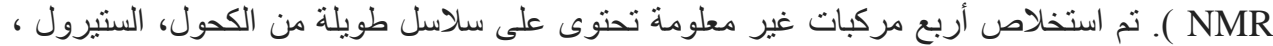

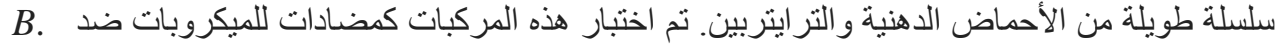

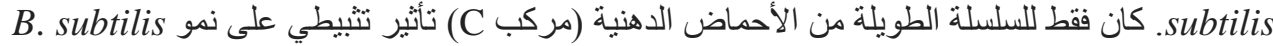
بينما كانت المركبات الأخرى غير فعالة. 